\title{
Kani Mikaiil: a seasonal cave site of the Middle Neolithic period in Kurdestan, Iran
}

\author{
Kourosh Roustaei, Hassan Rezvani \& Saman Heydari*
}
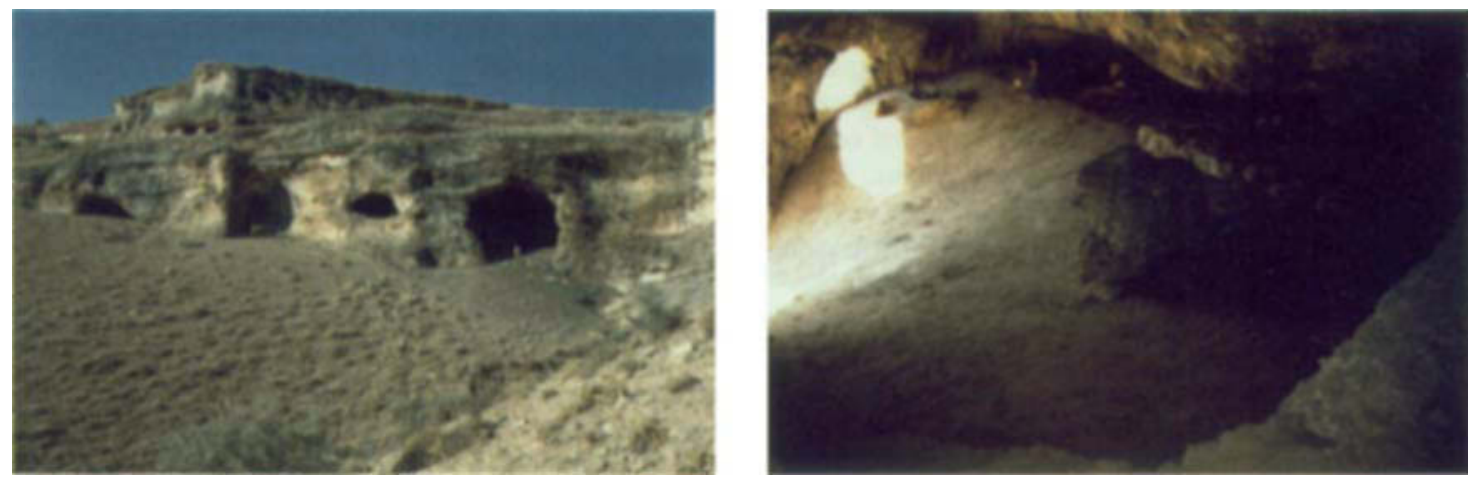

FIGURE 1 (above, left). Kani Mikaiil, general view.

FIGURE 2 (above, right). Inside view of the cave. TT1 and TT2 are seen respectively at upper left and upper right of the picture.

After several years of hiatus in Palaeolithic research in Iran, increasing activity in this field began in the early 1990s (see among others: Biglari 2000; Biglari \& Heydari 2001; Roustaei et al. 2002). Although the Zagros Mountains in western Iran were the main focus of the previous archaeological fieldwork, there still remain in the region areas that are not archaeologically well known. With the exception of the two sites of Ziwiyeh and Karaftoo cave, the province of Kurdestan in western Iran is one of these lesser-known areas.

With this problem in mind, when Mr Hassan Rezvani, director of the Karaftoo cave Project, invited us to participate in the excavations, we took the opportunity to join him to investigate the potential of the region for archaeological evidence pertaining to Palaeolithic life. Following an initial survey of a number of potential cave sites near Karaftoo cave, we selected Kani Mikaiil cave for testing. The excavations were conducted from early September to mid October 2001.

From the beginning, we were aware that because of high elevation (c. $2100 \mathrm{~m}$ ) the region might not be rich in Palaeolithic remains. Our reason for this uncertainty was based largely on the fact that, according to some palaeoclimatic evidence,

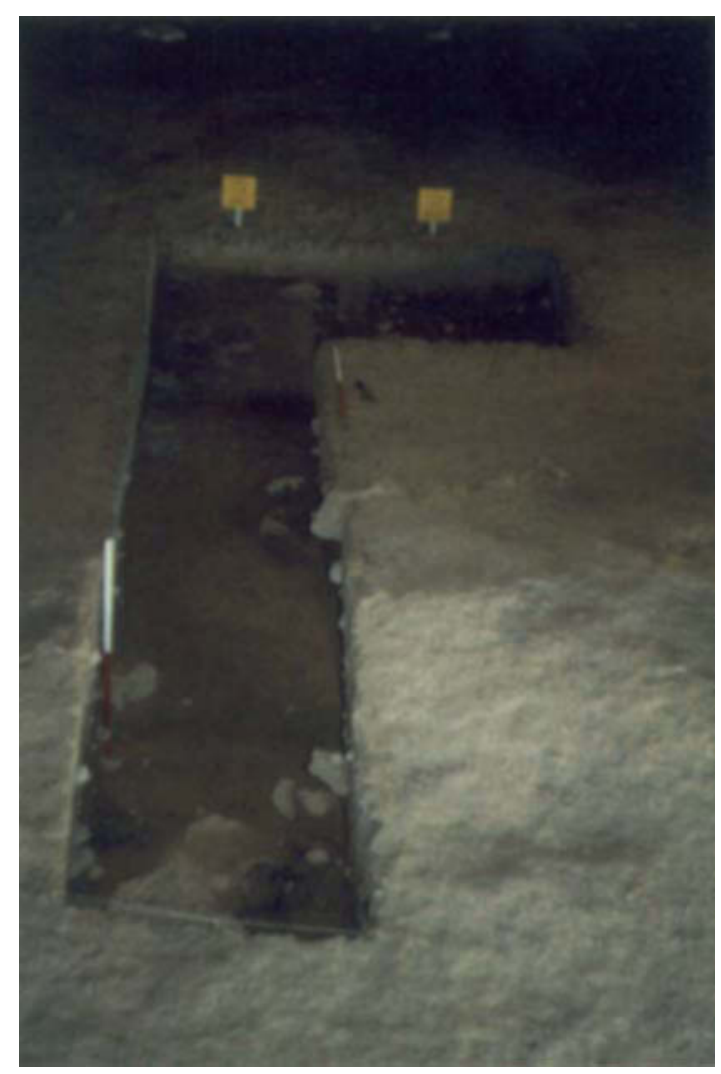

FIGURE 3. General view of TT2 and TT3.

* Roustaei \& Rezvani, Center for Archaeological Research, Iranian Cultural Heritage Organization, Zanjan Street, Azadi Avenue, Tehran, Iran. Heydari, Center for Palaeolithic Research, National Museum of Iran, Siye Tir St., Imam Khomeini Avenue, Tehran, Iran. 
the snow line in the Zagros during the Pleistocene was at about 1200-1800 $\mathrm{m}$ a.s.l. (Wright 1983). Even today, Kurdestan is famous for its harsh winters and heavy snow falls.

Kani Mikaiil cave is located some $40 \mathrm{~km}$ east of the city of Saqiz, and about $2 \mathrm{~km}$ north of Karaftoo cave. Kani Mikaiil lies in a rock cliff at the end of a small side valley. The predominant geological formation of the region is plio-quaternary clay stone, sandy limestone and conglomerate. The entire landscape is composed of rolling hills that are interrupted by small plains. In our survey area, no apparent source of chert or other high-quality raw materials for manufacturing stone tools were found.

Kani Mikaiil is a relatively spacious cave ( $c$. 712 sq. m) with two openings (FIGURE 1). In plan it is somewhat elliptical, about $41 \mathrm{~m}$ wide, $29 \mathrm{~m}$ deep, and with a maximum height of $c .10 .5 \mathrm{~m}$ in the middle of the cave. An overhang separates the apron of the cave from its rear section, which decreases in height as one proceeds to the back of the cave, and which protects this section from the elements. The topography of the cave floor varies considerably; while the rear half of the cave has an almost level floor, the front part is steep toward the main opening (FIGURE 2). A small depression $(30 \times 30 \times 20 \mathrm{~cm})$ filled with stagnant water is located in the back of the cave. According to the locals, this depression periodically becomes a small spring during times of high precipitation; a small stream drains the water through the slope of the apron in the front. Because local shepherds use the cave to shelter their herds, its floor is covered with a thick layer of dung.

We made three small test trenches (TT) in the cave: TT1 (1×3 m), near the smaller opening; TT2 $(1.5 \times 1.5 \mathrm{~m})$, a few metres further under the overhang; and TT3 ( $1 \times 6.5 \mathrm{~m})$, just beside TT2, between TT1 and TT2. Sounding TT1 yielded exclusively natural deposits. However, to obtain geological samples, we excavated the sounding to the bed rock, $2 \mathrm{~m}$ deep. Soundings TT2 and TT3 yielded cultural remains dating to the Dalma phase of the Neolithic Zagros (c. 5th millennium BC), as rvell as to historical and Islamic periods (FIGURE 3). The distribution of the artefacts in the cave indicated to us that the ancient inhabitants of the cave naturally preferred the more protected part of the cave, under the overhang. In both soundings the thickness of the cultural deposits varied from 50 to $80 \mathrm{~cm}$.

To extract as much data as possible from the remains, all the excavated soil was sifted, using two different-sized screens. Pottery was the most common find, including the typical Dalma Im- pressed and Red-burnished wares. Other finds include a number of stone artefacts made of flint and obsidian, some pieces of glass, two tiny bronze pieces of uncertain shape, a plain cone-shaped clay spindle whorl, and a small lump of red ochre. No solid architecture was found; instead, numerous burnt floors and an accumulation of ashes occurred, indicating temporary use of the cave. We subjected over 20 litres of sediments to flotation,which yielded only a handful of charred seeds. Analysis of the seeds revealed that they were domesticated barley (Hordeum vulgare), domesticated emmer (Triticum dicoccum) and bread/ hard wheat (Triticum aestivum/durum). The faunal remains are being analysed by Dr Marjan Mashkour of CNRS, Paris. The lithics were studied by Fereidoun Biglari, who also participated in the excavations.

As we suspected, no Palaeolithic materials were recovered in the cave. The excavation, however, revealed the oldest known occupation in Kurdestan province. In addition, as some researchers previously pointed out (e.g. Henrickson 1985), we now have good evidence of a seasonal cave occupation of the Middle Neolithic in the Zagros Mountains. While this evidence could enhance our understanding about the origins of this type of occupation in western Iran, future research will be concentrated on finding Palaeolithic sites in the region.

Acknowledgements. We wish to thank many individuals who generously helped us during the various stages of research. Abbas Alizadeh (University of Chicago) read the various drafts of this article and took the charred seeds for analysis to US. Naomi Miller (MASCA) kindly accepted to analyse the floral samples; Jalil Golshan (Research Deputy of Iranian Cultural Heritage Organization, ICHO) and Dr Masoud Azarnoush (Director of the Center for Archaeological Research of ICHO) for allowing us to publish our preliminary results; and, finally, Mohammad Ebrahim Zare'ei and Rasoul Oshtoudan (both of the CuItural Heritage Office of Kurdestan Province) for encouragement and much support during the fieldwork.

\section{References}

BIGLARI, F. 2000. Recent finds of the Palaeolithic period from Bisotun, Central Western Zagros Mountains, Iranian Journal of Archaeology and History 28: 50-60. (In Persian with an English summary.)

BIGLARI, F. \& S. HEYDARI. 2001. Do-Ashkaft: a recently discovered Mousterian cave site in the Kermanshah Plain, Iran, Antiquity 75: 487-8.

HENRICKSON, E.E. 1985. The early development of pastoralism in the Central Zagros (Luristan), Iranica Antiqua 20: $1-42$.

ROUSTAEI, K., F. BIGLARI, S. HeYDARI \& HAMAD VAHDATI NASAB. 2002. New research on the Palaeolithic of Lurestan, West Central Iran, Antiquity 76: 19-20.

WRIGHT, H.E. 1983. Climatic change in the Zagros Mountains - revisited, in W. Braidwood, R.J. Braidwood et al. (ed.), Prehistoric archaeology along the Zagros Flanks: 505-10. Chicago (IL): Oriental Institute, University of Chicago. 